\title{
Developments of and Challenges to Basic Research Funding in Science and Engineering Sectors of Korea: The Role of National Research Foundation of Korea (NRF)
}

\author{
In-Soo Han ${ }^{1}$, Hwa-Yong $\mathrm{Ahn}^{2}$, Byung-Whan $\mathrm{Ho}^{2}$ \& Keun-Yeob $\mathrm{Oh}^{3}$ \\ ${ }^{1}$ Department of Business Administration, Chungnam National University, Daejeon, Korea \\ ${ }^{2}$ National Research Foundation of Korea, Daejeon, Korea \\ ${ }^{3}$ Department of International Trade, Chungnam National University, Daejeon, Korea \\ Correspondence: Keun-Yeob Oh, Department of International Trade, Chungnam National University, Daejeon, \\ Korea. Tel: 82-10-2558-7805. E-mail:kyoh@cnu.ac.kr
}

Received: June 14, 2014 Accepted: August 15, 2014 Online Published: October 30, 2014

doi:10.5539/ass.v10n22p117 URL: http://dx.doi.org/10.5539/ass.v10n22p117

\begin{abstract}
Today, Korea faces a new challenge in the field of basic research: the country has attained a goal in terms of the amount of growth, but it needs to improve its quality of research. Korean researchers need to demonstrate excellence in their research, a far more critical issue than the number of papers published. Considering the current research ability in the country, they also need to show more creativity and forge better links with business.

This paper calls for a new policy on research within basic science and technology, at a turning point in the history of research funding in Korea. In particular, it explains the development of research funding focusing on the NRF's role, discusses the performance of and some problems in research funding, and finally makes recommendations for an NRF funding policy that could usher in a new era of research excellence in Korea. We hope this paper will help construct a theoretical framework for a basic research funding system for science and technology in Korea. In addition, we expect this paper will give some practical guidance for other developing countries trying to foster R\&D capabilities in basic science.
\end{abstract}

Keywords: basic research funding, basic science and technology, research grant, National Research Foundation of Korea, NRF, Korea

\section{Introduction}

Korea obtained an outstanding economic growth during last fifty years, which often described as a miracle. After the Korean war of the early 1950's, Korea was standing almost on nothing, but now per capita GDP is much higher than twenty thousand dollars and the size of Korean economy ranks $11 \sim 12$ th in the world. Korean economy is now considered by many developing countries as their role model.

This miracle would have not been possible without the technology development and R\&D expenditures of public and private sectors. Actually the export items of Korea were limited to clothing and wig in 1960s, but now high tech like telecommunication, semiconductor, LCD became main exporting industries for Korea. (Han \& Oh, 2013; Han et al., 2012)

Considering that the competitiveness of the products depends on the science and technology, Korean government put big R\&D investment into science and technology area since 1970s. In particular, Korean government has been putting a lot of money into the basic science area as well as applied science area. In 1977, KOSEF (Korea Science and Engineering Foundation, now renamed as NRF) was established and it became to a large and important organization for the R\&D in Korea. NRF has various programs for supporting the research of Korean researchers and total budget size of NRF is more than 3.7 billion dollars as of 2014. As a results of the efforts, SCI papers, one of the index for the research level, ranked 11th in the world in 2012 while it was 18 th in 1999 (MSIP, 2013).

Nowadays, Korea faces a new challenge for the basic research area. That is, Korea attained a goal in terms of quantity growth but it needs a take-off for the research quality. Korean researchers should show the excellence of 
the research which is something more critical than the number of published papers and should show more creative ideas and businessization based on the accumulation of research ability.

This paper looks for a new policy for the research of basic science and technology at the turning point of research funding history in Korea. In particular, we explain the development of research funding history, focusing on NRF's role, and we discuss the performance and some problems in research funding and finally suggest the recommendations for funding policy of NRF toward the new era of research excellence in Korea. We hope this paper can contribute to construct a theoretical framework of the basic research funding system for the science and technology. In addition to this, we expect this paper can give some practical guidance for other developing countries trying to foster R\&D capabilities in basic science.

\section{Development of Basic Research Funding in Korea}

\subsection{Establishment of KOSEF and Individual Research Funding}

\subsubsection{Establishment of KOSEF (1977-)}

Since 1960s, Korea has invested for the science and technology under the recognition of the importance and necessity of science technology, and the establishment of Korea Institute of Science and Technology (KIST) of 1966 was the first step toward this direction. However the initial focus of R\&D was on the development of manufacturing technologies at that time. Afterwards, Korea recognized the importance of basic technology and science as the Korean industry was getting more capital and technology intensive. Accumulation of the research in basic science \& technology in the universities and research institutions was considered as necessary for further long term development of Korean economy and industry.

This was the background for Korean government to establish Korea Science and Engineering Foundation (KOSEF) in May of 1977. This institution modeled on National Science Foundation (NSF) of America. The establishment of the foundation seemed to have been a big step for the infrastructure for the basic research. At first, however, the size was very small; research fund was only 418 million KRW (about US\$408,000) in 1978.

\subsubsection{The Individual Research Funding (1978-)}

The first funding program for the basic science by KOSEF was the support for the individual researcher. The researchers in the university and other research institutions applied for the grant and KOSEF evaluated the proposals and some of the proposals were selected to be financially supported. At first, the one-year project was supported, but it was extended soon to support the up to three-year projects.

There were two kinds programs; general researcher program and young researcher program. The former was encouraging the basic research and extending the research base. The latter was for the new researchers who got the job in the university after getting $\mathrm{Ph}$. D. and supported for the settling down in the new environment.

\subsection{The Co-research Funding (1982-)}

In 1982, Korean government started a new funding program for the co-research projects. Particularly, the research project in urgent need at national level was funded, and thanks to this, cooperation among academics, industry, and research institution were encouraged. At that time, semi-conductor, computer, fine chemistry, mechanical engineering, energy and natural resource, system industry, bio engineering, fiber polymer material, construction, and environmental industry were designated as the core and urgent nine areas for the intensive support. Korean government put all the resources for this project and hoped to be able to accumulate the research experience and to rise up the competent researchers. In addition, a little bit larger size groups of five to six people were supported since 1986, and labor charges for the post-doctoral and Ph.D. students and master students could be paid from the research grant, which could encourage the training of next generation researchers.

\subsection{The Group Research Funding (1990-)}

\subsubsection{Science Research Center (SRC) and Engineering Research Center (ERC) (1990-)}

From 1990's, KOSEF began to support the establishment of research centers in the universities in order to encourage basic research the long-term. The projects were trying to centralize the research manpower in a center of the universities by the areas and encourage the basic science research and develop the man power. Actually, this project was benchmarking STC (Science Technology Center) and ERC (Engineering Research Center) of NSF (National Science Foundation) in U.S. which was considered very successful. KOSEF used same names $\mathrm{SRC}$ and ERC for the projects.

The SRC (Science Research Center) was trying to support the high quality paper publications, which might 
enable the deep and creative research in the basic science area. ERC (Engineering Research Center) was founded for the basic research in the area of high tech industry. This ERC project supported the original technology of international level and encouraged the interdisciplinary research based on the cooperation of academic-industry with the hope of improvement of the international competitiveness of the industries. These research center projects are evaluated to have contributed a lot for cultivating the researcher group, for helping the basic research, and university-industry cooperation.

Since this decade, research funding by KOSEF has been categorizing into two areas; individual research programs and group research programs.

\subsubsection{Regional Research Center (RRC)(1995-2004)}

In 1995, KOSEF launched another funding program; RRC (Regional Research Center). This project funded the universities in non-capital (Seoul) area and established research centers there. Basic and applied science research related with the core industries of the local areas was funded by RRC of KOSEF. This RRC is specialized for the research helpful for meeting the local industry needs and tries to transfer the technologies developed by the research to the industrial side. RRC project had an additional program; when the firms asked the centers to develop the specified technology for them, the R\&D costs for development had to be paid for by the firm themselves.

A unique characteristic of this project was the technology development for the industry. It might not accord with the original mission of KOSEF, which mainly foster the basic science research. For this reason, this project eventually moved to under the control of MTIE (Ministry of Trade Industry and Energy) which has the power of controlling over all the industrial technologies in 2004. Afterwards, this project was renamed as RIC (Regional Innovation Center) and has been in progress until now.

\subsubsection{MRC (Medical Research Center) (2002-)}

From 2002, KOSEF launched MRC (Medical Research Center) program and funded the basic research which could be used for bio-engineering and clinical medicine areas. This program was founded for the purpose of supporting the basic medical science by funding the medium- and large sized, long term research and development in medical sectors.

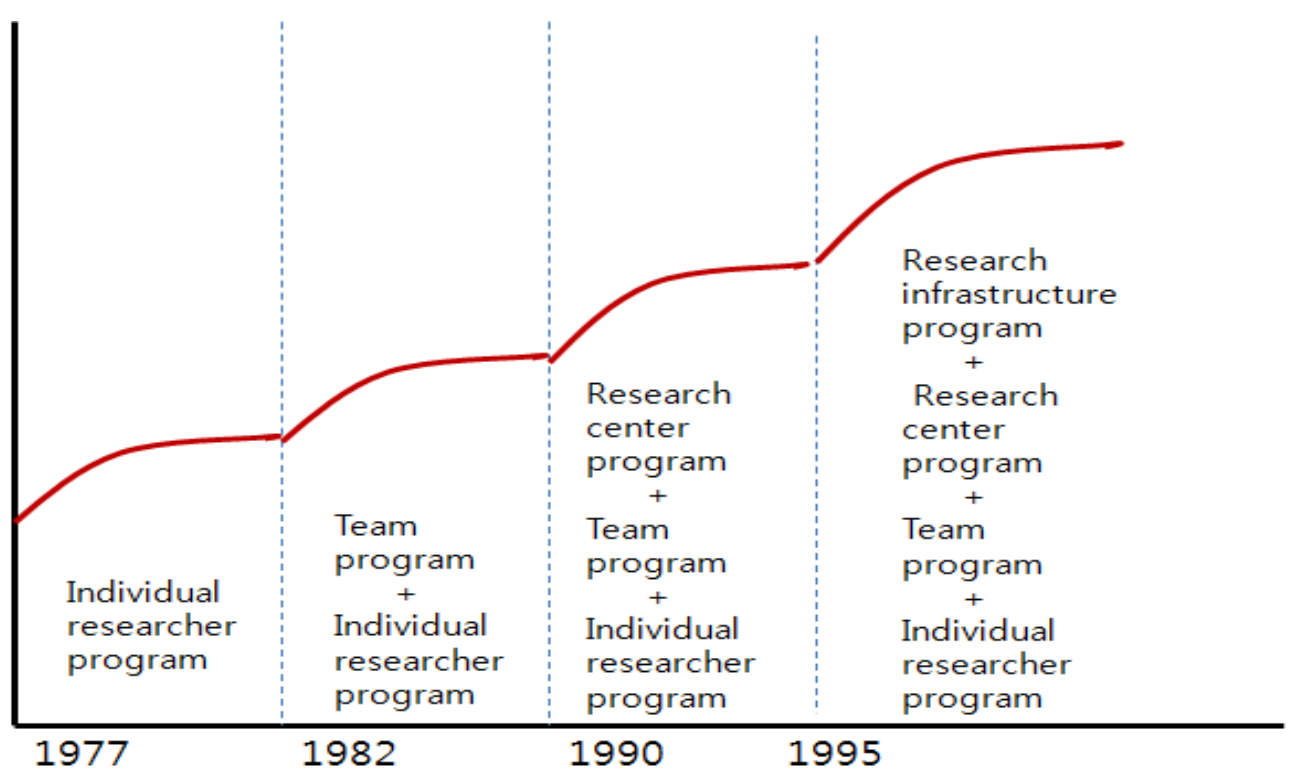

Figure 1. Developments of basic research funding by KOSEF

\subsubsection{NCRC (National Core Research Center) Program (2003-)}

In addition, NCRC (National Core Research Center) program was launched in 2003, which was going to encourage the development of the converging technology for future. The annual budget of KRW 2 billion (about US\$ 195,000) was funded to the each selected centers for 7 years ( $4+3$ years). 


\subsection{Support for the Research Infrastructure (1995-)}

In 1995, a program for building of the research infrastructure was launched. Very expensive machines, materials, research database which individual researchers could not buy by self-payment were purchased by using the fund, concentrated in one facility and shared by researchers. Actually this project supported some core universities specialized on certain disciplines.

This program consisted of three sub-projects; supports for the specific research material banks, supports for the specialized research information centers, and the supports for operation of high price machines and equipment's for research. Now the first two programs are underway.

Figure 1 illustrates the development process of basic science funding program by KOSEF, which added new programs sequentially.

\subsection{Extensions and Deepening of Individual Researcher Programs}

In addition to the development stages shown in Figure 1, there have been many horizontal and vertical evolutionary progresses in the funding programs for the individual researchers. These advances were based on the necessities for upgrading the capabilities of individual researchers

\subsubsection{Funding for Researchers in Local Area and Female Researchers}

Since 2000, new funding programs for the basic research by the researchers in local area (non Seoul area) and female researchers have been introduced. This project was launched by the recognition that the researchers in local areas and female researchers have been less represented as grant receiver compared with the portion of those researchers in the whole country and they were suffering from unequal support. According to Han et al. (2013), the share of research fund for regional researchers was only $40 \%$ of total NRF research fund while they accounted for more than $60 \%$ of university education in terms of the number of students and professors. And the female researchers account for only $17 \%$ of researchers of science and engineering area in the universities and the research institutes including government sponsored and private. Furthermore, only $13.2 \%$ of the research fund goes to female researchers (Han et al., 2012).

\subsubsection{Leading Researcher Program}

The next concerns of KOSEF were to support the distinguished individual researchers who could lead the academics in future. KOSEF liked to support those researchers in longer and larger view. Therefore, two new programs, 'Creative Research' of 1997 and 'National Scientists' of 2005 were designed for those purpose. The former aimed at discovering next-generation researchers and fostering them to become global leaders. The latter was supposed to support distinguished researchers to become key players in their specialized fields.

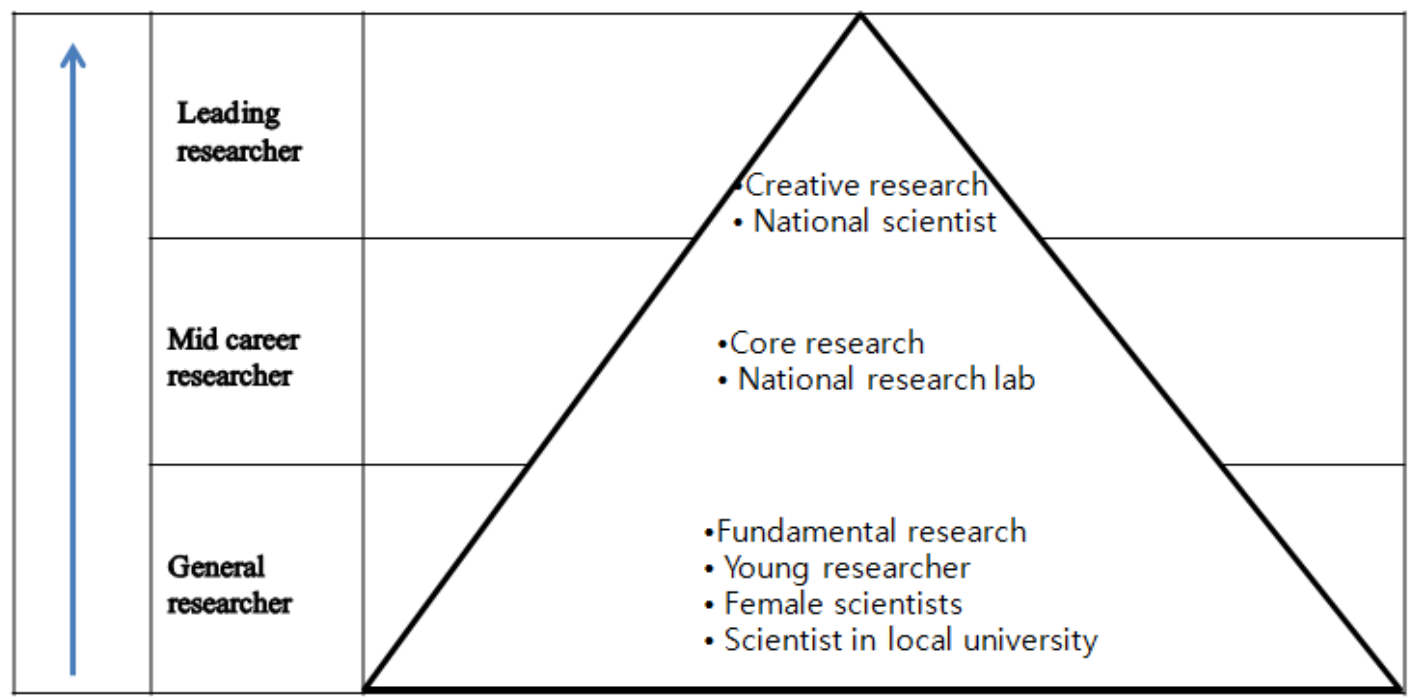

Figure 2. Building life cycle support system for individual researcher in basic research

Source: MSIP (2013a). 
Funding term was 9 years long $(3+3+3$ years $)$ for Creative Research and 10 years $(5+5$ years $)$ for National Scientist. KRW 500 800 million (US\$ 488,000 780,000) per project (Creative Research) and KRW 1.5 billion (US\$ 1.46 million) (National Scientist) were granted. In Creative Research, low 15\% were dropped out of the funding through the evaluation process in every three years. National Scientist project selected and supported one or two scientists every year.

\subsubsection{Systemization of Funding Programs for the Individual Research}

In 2009, KOSEF which had supported the researcher in science and engineering fields merged with another funding organization, KRF which focused on pure natural science and humanity or social science area. A new body was named as National Research Foundation of Korea (NRF). This merge was a turning point for systemization of the support programs for the individual researchers. That was so called 'support for whole life cycle of research'. Figure 2 shows those stages from General researcher program via Mid-career researcher program to leading researcher program.

\section{Changes in Governance for Basic Science Research Funding}

\subsection{KOSEF}

Since 1960s, KOSEF had had a critical role in developing science and technology. But its actual functioning had been under the control of Korean government, as Korean economic development was initiated by government. Fostering Science and technology in Korea was also initiated by the Korean government and it can be called 'government-driven'. In 1967, Ministry of Science and Technology (MOST) was established and this ministry planned a lot of programs for science development in Korea. So it can be said KOSEF was under MOST's control in that MOST provided the budget to KOSEF, and KOSEF had played a role to execute planned programs by using the money.

\subsection{Korea Research Foundation: KRF}

In 1981, Korea Research Foundation (KRF) was established under Ministry of Education (MOE). KRF was basically supposed to support humanities and social sciences area. This foundation also supported some basic science area related with cultivating the manpower. In 1999, some programs of KOSEF supporting basic science in science and engineering area moved to KRF. As a result, support for basic research in science and engineering had been done by dual system of KOSEF and KRF.

\subsection{National Research Foundation of Korea: NRF}

In 2009, the dual system of KOSEF and KRF ended since there was the merge of two control towers. MOST and MOE merged together into Ministry of Education and Science Technology (MEST). As a result, the funding organizations, KOSEF and KRF also merged into National Research Foundation of Korea (NRF). NRF now is the only foundation even after MEST split up into two ministries again after the new government launched in 2102, as shown in Figure 3.

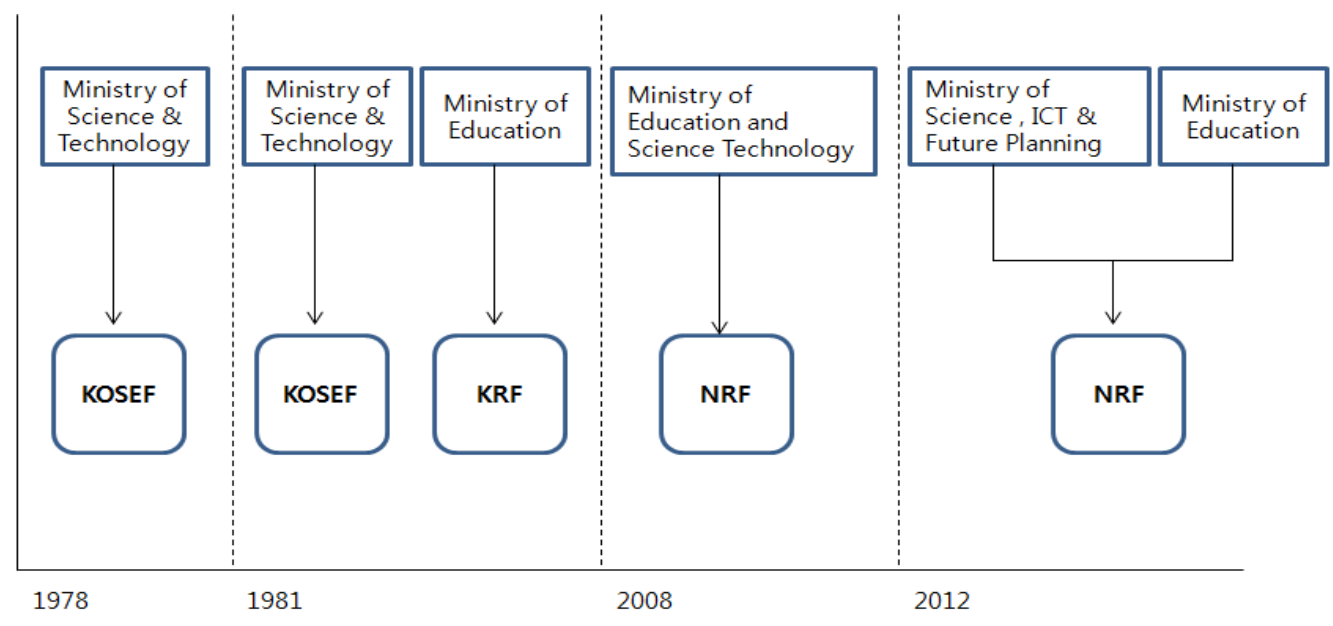

Figure 3. Changes in governance system for basic research funding 


\subsection{Dual Regulation for Basic Research Funding}

In 2012, Park's government reorganized the ministries and separated MEST into two ministries; Ministry of Science, ICT \& Future Planning (MSIP) and Ministry of Education (MOE). One of the reason for the split was they thought that MEST did not do very well in concentrating the resources for science and technology. But NRF keeps one body even after the separation.

\section{Performances and Problems in Basic Research Funding}

\subsection{Performances of Basic Research Funding}

Korea has been focusing on R\&D compared to her economic size. The share of R\&D expenditure is $4.36 \%$ of GDP, which ranked first in the world in 2012 (OECD, 2014). Of course most of this R\&D is from industry side even though the investment for the basic research has been increasing persistently since 1970s. But, the ratio of basic research expenditure is only $18.1 \%$ of the average of OECD advanced countries. The ratio of the investment for each area 'basic, applied, and development' is 18:20:62, respectively (MSIP, 2013b). Roughly speaking, the expenditure for the basic research is not enough and it needs to be increased. Furthermore, $R \& D$ spending for basic research performed by higher education and government sectors accounts for only $20.6 \%$, $21.8 \%$ respectively of domestic expenditure on basic research, as illustrated in Figure 4. (OECD, 2013). This seems to reflect the short history of science and technology in Korea.

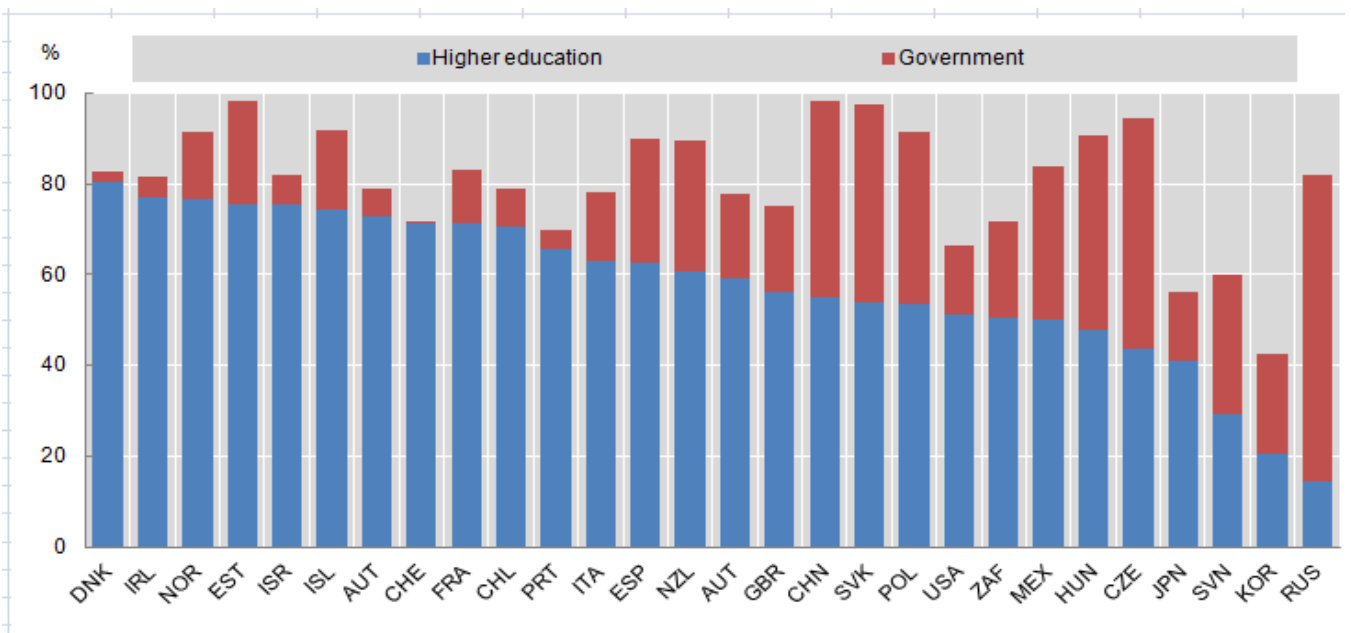

Figure 4. Basic research performed in the higher education and government sectors, 2013: As a percentage of domestic expenditures on basic research

Source: OECD (2013), Research and Development Statistics Database, www.oecd.org/sti/rds, June

But, Korean government recently came to recognize the importance of the basic research and tries to increase the investment for this area. Table 1 indicates that the share of basic research in the government fund increased from $25.6 \%$ in 2008 to $35.4 \%$ in 2013 (MSIP, 2013b).

Table 1. Share of basic research in government research fund

\begin{tabular}{llllllll}
\hline & \multicolumn{1}{c}{2008} & 2009 & 2010 & 2011 & 2012 & 2013 & growth rate \\
\hline Basic research & $\left(100 \mathrm{mil}_{1} 18,440\right.$ & 24,899 & 30,017 & 34,182 & 38,951 & 40,590 & $17.1 \%$ \\
KRW) & $25.6 \%$ & $29.3 \%$ & $31.1 \%$ & $33.1 \%$ & $35.2 \%$ & $35.4 \%$ & - \\
Share & & & & & & & \\
\hline
\end{tabular}

Source: MSIP (2013b).

Figure 5 shows the trend of the share of basic research since 1978 when KOSEF was founded (NRF, 2014). unit: KRW Mil. 


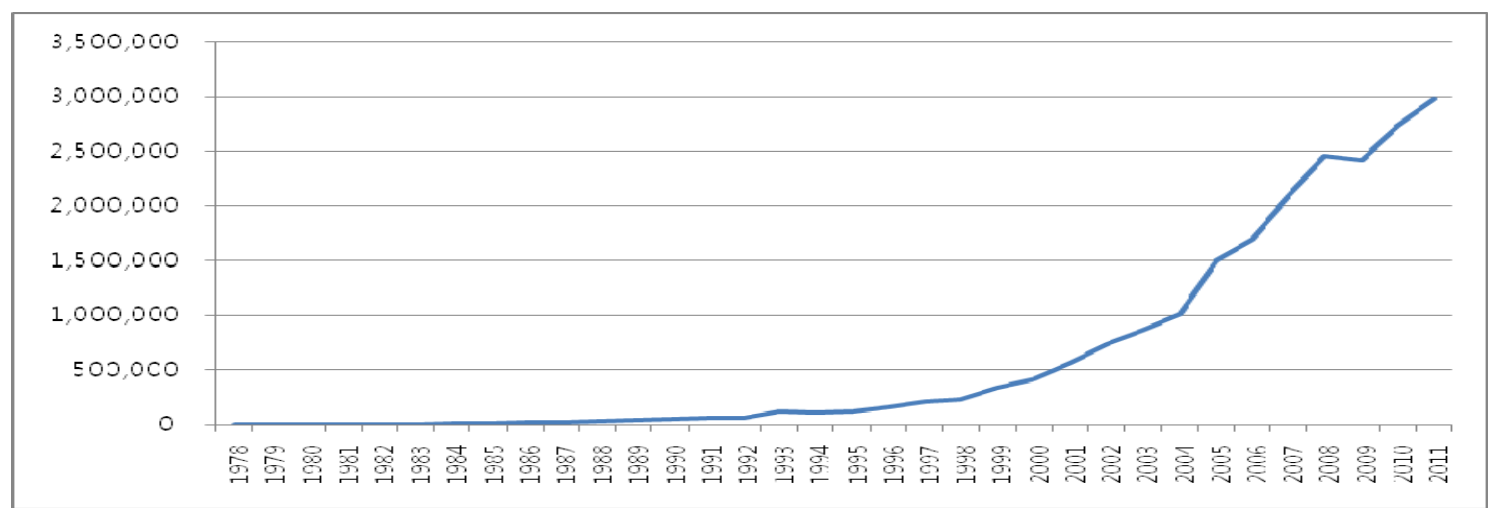

Figure 5. The trend of research funding by NRF (1978-2011)

Source: NRF (2014).

As shown in the Figure 5, research fund had increased a lot after 2000, which resulted in the budget of NRF 3,000 billion KRW (about 3 billion dollars) in 2013. 1/3 of this amount was spent for basic research.

Thanks to the sharp increase in the research expenditure, the number of the papers published in SCI journals have been increased a lot. In the Table 2, we can find that 44,718 papers were published in SCI level journal which means that Korea ranks 11 th in the world in terms of the number of the papers (MSIP, 2013b). Top 1\% of most frequently cited papers are 1,268 which ranked 15 th in the world. (Table 3 ).

Table 2. Number of SCI papers and ranking (\%)

\begin{tabular}{lllllll}
\hline & 2006 & 2007 & 2008 & 2009 & 2010 & 2011 \\
\hline no. of papers (rank) & $28,436(11)$ & $27,420(12)$ & $35,662(12)$ & $38,776(12)$ & $39,834(11)$ & $44,718(11)$ \\
no. of cited (rank) & $2.93(31)$ & $3.11(31)$ & $3.30(30)$ & $3.49(30)$ & $3.57(30)$ & $3.77(30)$ \\
\hline
\end{tabular}

Source: MSIP (2013b).

If we focus on the NRF of Korea, the number of papers published with research funding from NRF, increased from 12,833 in 2009 to 17,724 in 2100 , indicating the growth rate of $38 \%$. In particular, the number increase from 2,071 to 2,539 during same period if we focus on the top $10 \%$ high level journals in terms of impact factor (MSIP, 2013b).
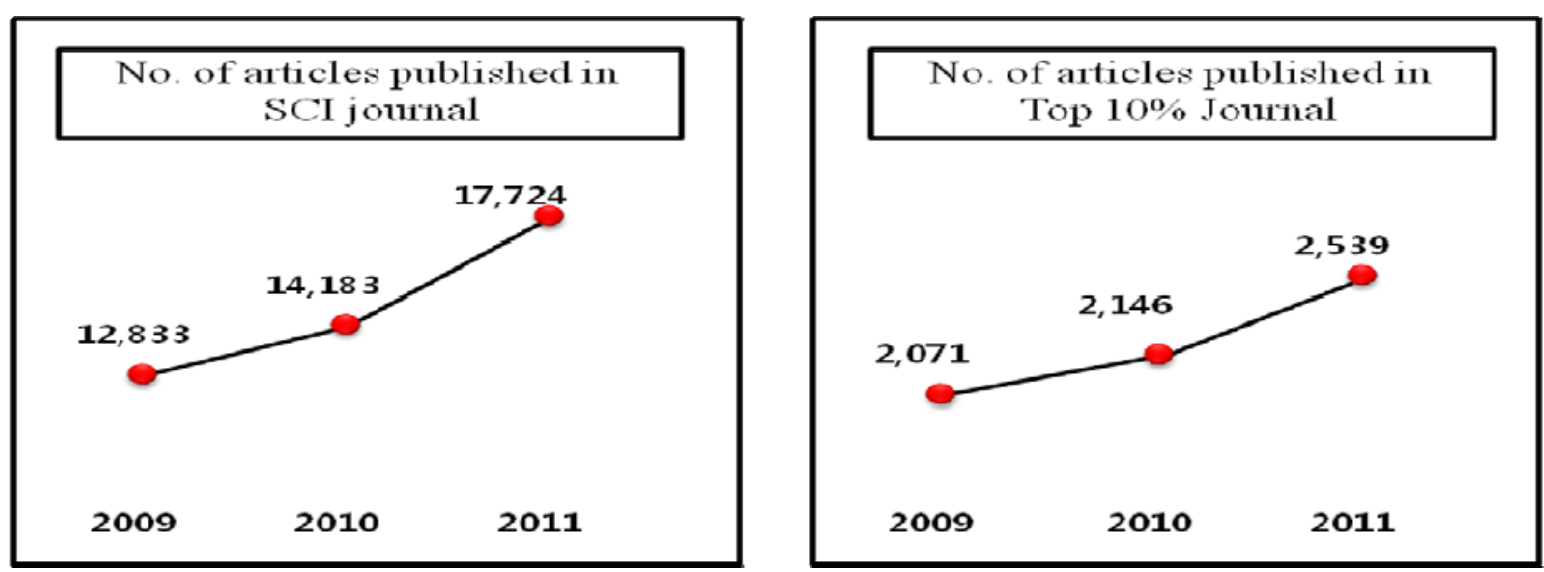

Figure 6. The Increase of articles published in SCI Journals by fund recipients

Source: MSIP (2013b). 


\subsection{Problems in Basic Research Funding: From Quantity to Quality}

Even though the number of published papers increased a lot, Korean researchers have long way to go in the view of the quality. Table 2 shows that Korea ranks 11 th as for the quantity but ranks 30th as for the citation of those papers (National Science and Technology Council, 2012). In addition in the Table 3 we could see the top 1\% cited papers were only $0.77 \%$.

Table 3. Top $1 \%$ of most frequently cited papers

\begin{tabular}{lllllll}
\hline & U.S. & U.K. & China & Japan & Swiss & Korea \\
\hline Number (rank) & $29,828(1)$ & $8,735(2)$ & $5,998(4)$ & $3,082(10)$ & $2,915(11)$ & $1,536(15)$ \\
Share & $1.79 \%$ & $1.81 \%$ & $0.86 \%$ & $0.82 \%$ & $2.62 \%$ & $0.77 \%$ \\
\hline
\end{tabular}

Source: National Science and Technology Council (2012).

The more serious problem is that the research results have not successfully gone to the next stage of the R\&D, say, technology transfer, businesszation, and business startup. Commercialization of the technologies developed from the research is very important for the economy; converting from the technology to wealth. But Korea is not that satisfactory in this sense compared to the more advanced countries. For example, the rate of technology transfer from universities among total technology transfer is just $16.4 \%(2011)$ in Korea, which is much lower than those of other countries cases such as $18.9 \%$ for Japan (2011), $25.4 \%$ for US (2010), and $25.2 \%$ for EU (2007), respectively (NRF, 2013).

Thus, the urgent tasks which NRF has to tackle now as to basic research funding can be summarized as two. The one thing is to make the quantitative outputs up to the qualitative performances. Another one is to support the transformation of the results from basic research to industrial use. NRF has to establish the appropriate policies and measures to support for these goals.

\section{Recommendations for Policy Change in Basic Research Funding by NRF}

As mentioned above, the task of NRF today is how to create the high quality outputs rather than just increasing the number of papers. NRF needs to re-engineer the programs and other supporting measures for this purpose. Some fundamental changes can be suggested in the following directions.

\subsection{From Program Funding to Block Funding}

Traditionally, research funding policy were made by the bureaucrats of Ministry (now, Ministry of Science, ICT and Future Planning or Ministry of Education) in Korea, and NRF implemented the policies by the authorization of Korean government. Therefore NRF could not make any programs or projects in the systematic way by itself. In addition, all the programs belong to a certain department of the ministry and the programs are supervised by the technocrats in each department.

This structure has the following problems. First, there could be the rigidity of using the budget and they could not respond quickly to the change in research funding demand. The budget for funding was locked up in a program and could not be transferred to other programs with budget crunch. It looks like many ponds of fund are there separately instead of a big and integrated lake. This could be barrier for getting appropriate use of the fund when there is a change in the situation. For example, the selection rates were $29.4 \%$ for the 'general researcher program' and $8.8 \%$ for the 'upper level researcher program' of 2013 (NRF, 2014). For the leading researcher program the ratio of selected proposal was only $2.0 \%$. This unbalance happened because flexible budget allocation among NRF programs had not been allowed until now.

Second, research funding was done based on programs not on academic disciplines. Thus it was not so easy to consider the idiosyncratic characters of each area. Overall, it is not too much say that the current funding system of NRF is supplier oriented system rather than recipient oriented system.

How to solve this problem? One of the solutions could be block-funding which many advanced countries already adopted (Chon \& Cha, 2011; AGDE, 2014). The government has control the total budget of research funding and allows NRF the autonomy to decide allocation of the fund among programs. This method has a couple of merits. First, NFR can respond easily when there is any change in circumstance. Second, thus, more efficient use of the budget will be possible. Third, each area of academic disciplines will be able to have their own portfolio for the expenditure. 


\subsection{From Program-based Funding to Discipline-based Funding}

Under the existing system of the research funding, NRF cannot consider the specific characters of each different academic area because of the uniform and rigid system in terms of each grant size and length of research period. For example, researchers in math area does not need very big money while some other areas need to buy quite expensive machines and materials even though both areas are classified as same area in the name of basic natural science. Now a new system for NRF can be offered as shown in Figure 7 which focuses on the transition from program-based funding system to discipline-based support system.

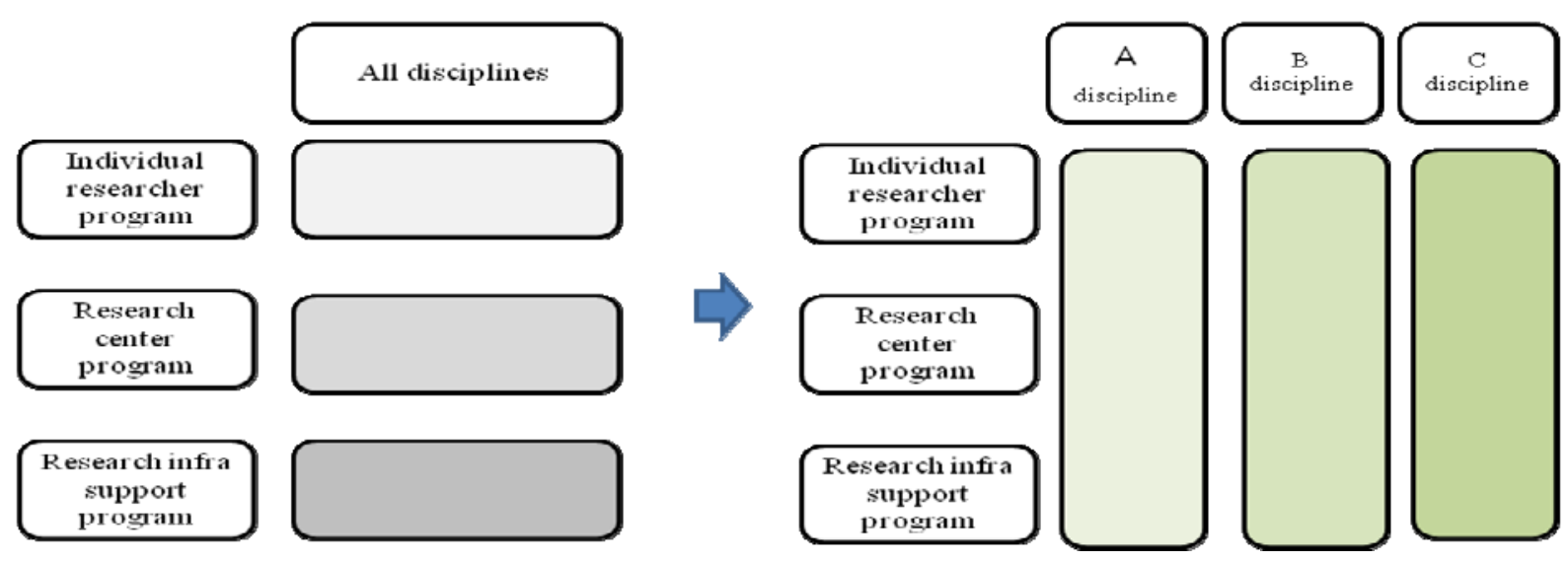

Figure 7. Transition to discipline-based support system

This new system will make NRF possible to develop the customized system meeting the specific needs of individual discipline (NYSCA, 2014). For the transition to new system, some supplementary action is needed in NRF like establishing a new 'committee for basic research fund operation'. The committee consists of experienced members in budgeting and can settle the conflicts on budget between disciplines. In addition, the experts in individual area should be able to plan the funding strategy and customized programs in their own disciplines.

\subsection{From Designated Mechanism Mode to Responsive Mode}

Funding methods for the programs should also change. The current funding method depends on so called designated mechanism mode. That is, the size of the fund and length of the research period are fixed depending on the programs. Change to a responsive mode funding need to be pursued to give researchers more flexibility and autonomy. Responsive mode means that research fund is provided on researcher's demand. Responsive mode is for unsolicited research proposals submitted by anyone eligible to apply to foundation for funding at any time and in any field of research relevant to foundation's remit (EPSRC, 2014).

Then, researchers can do their research in self-directed way and research funding would be possible in very various ways. For example, in the general research program, the funding rules for mathematics area have been same as other areas. Selection rate was uniformly about $25 \%$ and the size of the grant was fixed at 50 million KRW (US\$48,800). In contrast, under the new responsive mode funding, size of the grant could be flexible from 10 million (US\$9,800) to 50 million KRW and the selection rate can be increased up to $45 \%$ in mathematics area.

\subsection{From One-time Funding to Continuous Renewal Funding}

In the current NRF system, if one researcher wants to continue his (her) research topic, then he (she) has to make another new proposal and apply for another time with that. It could be time consuming and unduly burdensome for the researchers to write a new proposal even though the proposal is just for the continuation of the research. This situation can be avoided appropriately by adopting research renewal system based on the performance of the previous research. If the current research shows good performance, then the researcher can pursue identical research topic by submitting of a very brief and simple application (NSF, 2013). This would make possible the long term and high quality research.

As a matter of facts, this new system was already introduced in NRF in 2012 (MSIP, 2013a). As shown in Figure8, researcher who finished successfully the 'general research' could be funded up to another 3 years and 
can apply for the 'core research' of 'mid-career research', of which the research grant is larger than general research. Some excellent projects are going to be funded for another 3 years and can apply for the next step program, 'leap research'. After this, distinguished researchers can renew two times more in the 'leap research'. Theoretically, researchers can be funded up to 21 years by one topic in this new system; general research for 6 years $(3+3)$, core research for 6 years $(3+3)$, and leap research for up to 9 years $(3+3+3)$.

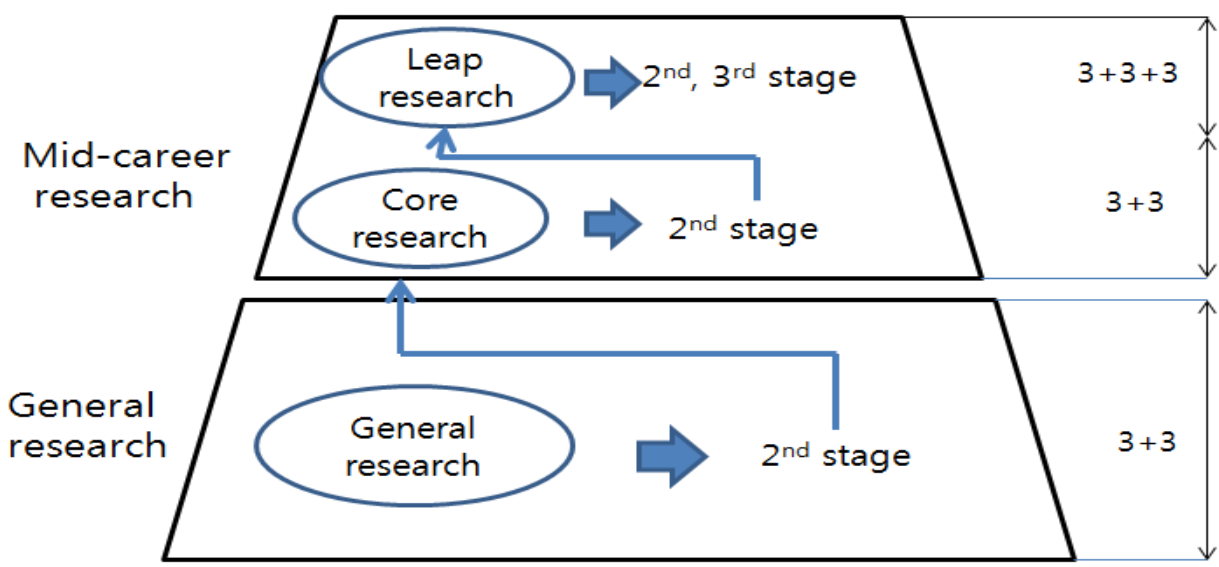

Figure 8. Continuous renewal funding for distinguished research plans

Source: MSIP (2013a).

\subsection{From Program Based Organization to Discipline Based Organization}

Organizational structures of NRF also need to be changed a lot for realizing all the suggestions explained above. NRF's current organization is basically program-based organization. But this system should be changed to discipline-based organization and this new organization should take charge of entire cycle funding activities (planning, executing, and evaluating) by disciplines. Of course, for the effective functioning of this new system, the expertise of NRF staffs should be strengthened, in terms of academic disciplines as well as project management. NRF needs to have a systematic and long term plan for how to level up the job competencies of staffs. Competency modeling and career development plan (CDP) for the staffs are requested. Table 4 summarizes all the issues above.

Table 4. Transformation of basic research funding by NRF

\begin{tabular}{lll}
\hline & As-is & To-be \\
\hline Funding & $\bullet$ Program funding & $\bullet$ Block funding \\
Budget & $\bullet$ Program based & $\bullet$ Discipline based \\
Funding & $\bullet$ designated mechanism mode & $\bullet$ Responsive mode \\
Administration & $\bullet$ one-time & $\bullet$ Continuous renewal \\
NRF organization structure & $\bullet$ Program based & $\bullet$ Discipline based \\
\hline
\end{tabular}

\section{Conclusion: Waiting for a First Nobel Prize Winner}

This paper dealt with the development of NRF's basic research funding and its role in boosting science and technology in Korea. Performances it has achieved and the problems it encounters were also discussed. Finally, based on these discussions, recommendations for needed changes in basic research funding in NRF were suggested.

In the paper, a transition from the quantitative performance to the qualitative performance is emphasized. Particularly, improvement of capacity for the long term basic research is much important than the number of research papers published. Some suggestions for this change are suggested as following; block funding, discipline-based funding, responsive mode, continuous renewal support. In addition, the organization of NRF needs to be transformed focusing on the discipline based organizational structure. 
Since KOSEF was established and began its support for the basic research in 1978, there has been a lot of investment for the research. As the results, Korea has big performance from the view of quantitative aspect as shown in the number of SCI level journal publications. Now Korea tries to take another leap for the breakthrough of basic research. Many Koreans long for the appearance of a first Korean Novel laureate in the basic research area, for it could be the sign that Korea obtains the quantitative performance. It is the time when NRF takes off once more.

\section{Acknowledgments}

This work was supported by research fund of Chungnam National University.

\section{References}

AGDE (Australian Government Department of Education). (2014). Research Block Grants. Retrieved April 5, 2014, from https://education.gov.au/research-block-grants

Cho, M. H. (2013). A Preliminary Study for 3rd Basic Research Master Plan (2013 2017). National Research Foundation of Korea (NRF).

Chon, Y. C., \& Cha, D. W. (2011). Trends in Block Funding in Leading Research Institutes. Korea Institute of Science \& Technology Evaluation and Planning (KISTEP).

EPSRC. (2014). Definitions of Funding Modes. Retrieved from http://www.epsrc.ac.uk/funding

Han, I. S., \& Oh, K. Y. (2013). The LCD Industry in East Asia: Competition and Cooperation among Japan, Korea, Taiwan and China. Lambert Academic Press.

Han, I. S., Oh, K. Y., \& Yoo, J. M. (2012). Changes in Competitiveness of LCD Industry of East Asia: From Bamboo Capitalism to Water Lily. International Telecommunication Policy Review, 19(1), 16-41.

Han, I. S., Oh, K. Y., Hwang, K. Y., \& Yoo, J. M. (2012). Developing Programs to support the University Scholars in Local Area and Female Scientists. Research Report, Korean Research Foundation.

Han, I. S., Oh, K. Y., Hwang, K. Y., Yoo, J. M., \& Park, K. S. (2012). An Analysis of Research Fund Divide in Korea. Journal of the Korean Regional Development Association, 24(3), 85-106.

Ministry of Science, ICT \& Future Planning (MSIP). (2013a). The Action Plan for Basic Research Funding in Science and Engineering 2013. Ministry of Science, ICT \& Future Planning.

Ministry of Science, ICT \& Future Planning (MSIP). (2013b). The Basic Research Master Plan (2013-2017).

National Institute for Health Research: NHS. (2014). Response Mode Research Programs.

National Research Foundation of Korea (NRF). (2013). A Report on Academic-Industrial Cooperation 2011.

National Research Foundation of Korea (NRF). (2014). Internal Data on Research Budget.

National Science and Technology Council. (2012). SCI Analysis Research.

National Science Foundation. (2013). NSF Proposal Award Policies and Procedures Guide: Part 1 Grant Proposal Guide.

NYSCA. (2014). About NYSCA Grants. Retrieved from http://www.nysca.org/public/guidelines/

OECD. (2013). OECD Science, Technology and Industry Scoreboard 2013: Innovation for Growth.

OECD. (2014). Main Science and Technology Indicators Database, January.

\section{Copyrights}

Copyright for this article is retained by the author(s), with first publication rights granted to the journal.

This is an open-access article distributed under the terms and conditions of the Creative Commons Attribution license (http://creativecommons.org/licenses/by/3.0/). 